\title{
Atlanto-occipital dislocation: case report and discussion
}

\author{
David A. McKenna, MB, MRCOG, MRCPI, FFRRCSI; Clare J. Roche, MB BCh, BAO, MRCPI, DMRD, \\ FRCR; ${ }^{*}$ W. Kit Lee, MB BS, FRANZCR; ${ }^{\dagger}$ William C. Torreggiani, MB BCh, BAO, LRCP\&SI, MRCPI, \\ FRCR, FFRRCSI; ${ }^{\dagger}$ Vinay A. Duddalwar, MB BS, MD, FRCR, DNB, MRad ${ }^{\dagger}$
}

\begin{abstract}
Atlanto-occipital dislocation (AOD) is a devastating condition that frequently results in prehospital cardiorespiratory arrest and accounts for $15 \%$ of fatal spinal trauma. Atlanto-occipital dislocation occurs 5 times more commonly in children than adults, and is believed to be caused by hyperextension. Because of improvements in prehospital resuscitation, more victims with AOD now survive to reach the emergency department. Neurologic injury is usually severe secondary to ligamentous disruption that allows the cranium to move with respect to the cervical spine, and associated facial and head injuries are common. There are, however, reports of survivors without neurologic deficits. We present the case of a 46-year-old woman who suffered an AOD after a motor vehicle crash and we discuss the diagnosis of this condition. The signs of AOD are often subtle, and the possibility of this diagnosis must be kept in mind in all patients with a neck injury, even in the absence of neurologic signs. A systematic approach to assessing the cranio-cervical relationship on the lateral cervical $x$-ray and the appropriate use of CT scanning is essential to identifying AOD. Through this case report we hope to familiarize clinicians with mechanisms of injury and appropriate imaging interpretation that will assist in the diagnosis of AOD.
\end{abstract}

Key w ords: atlanto-occipital dislocation; spinal trauma; neurologic injury; diagnosis of $A O D$

\begin{abstract}
RÉSUMÉ
La luxation occipito-atloïdienne (LOA) est une atteinte dévastatrice qui entraîne fréquemment un arrêt cardiorespiratoire préhospitalier et représente $15 \%$ des traumatismes rachidiens fatals. Ce type de luxation se produit cinq fois plus souvent chez les enfants que chez les adultes et on croit qu'elle est causée par l'hyperextension. Grâce à l'amélioration de la réanimation préhospitalière, un plus grand nombre de victimes de LOA survivent maintenant jusqu'à leur arrivée au département d'urgence. La lésion neurologique est généralement grave et découle de la rupture ligamentaire qui permet au crâne de se déplacer par rapport à la colonne cervicale et des blessures associées au visage et à la tête sont courantes. Cependant, on rapporte des cas où des victimes ont survécu sans déficit neurologique. Nous présentons le cas d'une femme âgée de 46 ans ayant subi une LOA après une collision en automobile et nous discutons du diagnostic de cette atteinte. Les signes de la LOA sont souvent subtils et la possibilité de ce diagnostic doit être gardé en tête pour tous les patients présentant une blessure au cou, même en l'absence de signes neurologiques. Une démarche méthodique lors de l'évaluation de la relation cranio-cervicale sur le cliché cervical latéral et le recours approprié au tomodensitogramme sont essentiels à l'identification de la LOA. Grâce à la présente observation, nous espérons familiariser les cliniciens avec les mécanismes de blessure et l'interprétation appropriée de l'imagerie qui contribueront au diagnostic de la LOA.
\end{abstract}

\footnotetext{
*Department of Radiology, University College Hospital Galway, Newcastle, Galway City, County Galway, Ireland †Department of Radiology, Vancouver General Hospital, Vancouver, BC
}

Received: June 7, 2005; final submission: Oct. 20, 2005; accepted: Nov. 9, 2005

This article has been peer reviewed.

Can J Emerg Med 2006;8(1):50-3 


\section{Case report}

A 46-year-old unrestrained female passenger was ejected from her seat following a high speed motor vehicle crash. She was unconscious at the scene and developed respiratory arrest en route to hospital, necessitating intubation and ventilation by the paramedic team. On arrival at the emergency department (ED) she had a Glasgow Coma Scale score of 7, and no spontaneous respirations. Her blood pressure, pulse and oxygen saturation were stable, and her only external sign of injury was a submental laceration.

A lateral cervical spine radiograph showed pre-vertebral soft tissue widening, malalignment between the cranium and cervical spine, and widening of the atlanto-occipital joint space to greater than $5 \mathrm{~mm}$ (Fig. 1). A cervical spine CT scan was performed that confirmed an atlanto-occipital dislocation (AOD).

The patient underwent operative fixation to stabilize the atlanto-occipital joint, and was weaned from ventilatory support over the subsequent 2 weeks. Her clinical status continued to gradually improve following operative fixation.

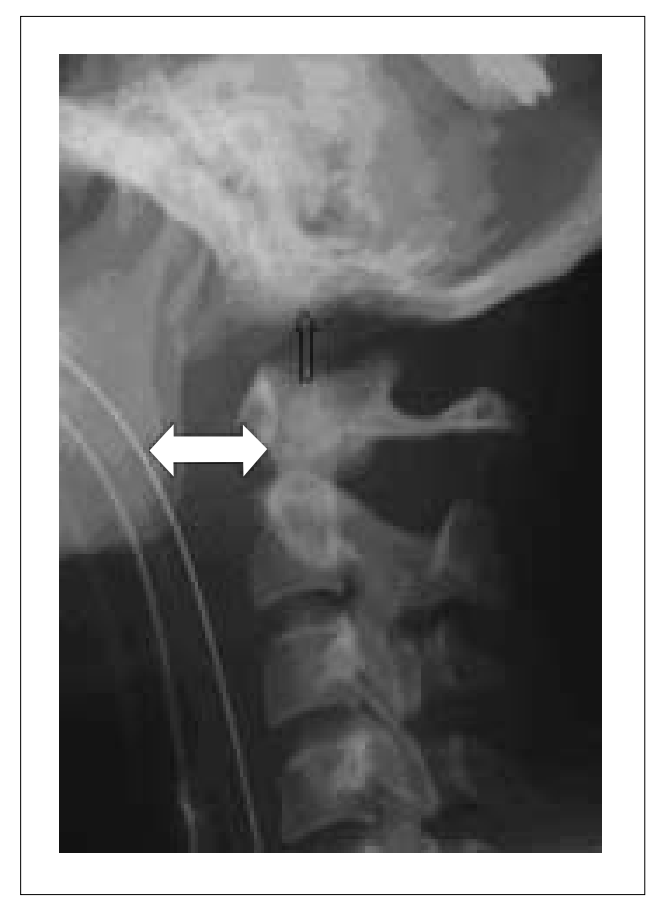

Fig. 1. Lateral cervical spine radiograph. There is prevertebral soft-tissue swelling (indicated by the larger white arrow) and malalignment between the skull and the cervical spine with widening of the atlantooccipital joints to more than $5 \mathrm{~mm}$ (highlighted by the smaller arrow).

\section{Discussion}

Atlanto-occipital dislocation accounts for $15 \%$ of all fatal spinal trauma, occurs 5 times more frequently in children than in adults, and is usually associated with severe brain injury. Motor vehicle crashes are the most common cause of AOD; however falls, direct trauma and forceps delivery can also result in this injury. ${ }^{1,2}$ The mechanism of AOD is believed to be hyperextension, and there is a high incidence of associated mandibular fractures and submental lacerations. ${ }^{2}$ Traumatic disruption of the apical and alar ligaments, and the tectorial membrane, allows the cranium to move with respect to the cervical spine. The most common patterns of occipito-vertebral dissociation are concomitant anterior displacement and distraction seen in $65 \%$, purely distracted in $19 \%$, purely anterior in $13 \%$ and purely posterior seen in 3\%. ${ }^{3}$ As a result of occipito-vertebral dissociation the medulla oblongata is left vulnerable to injury and can even be transected. ${ }^{1,3}$ Injury to this area frequently results in cardiorespiratory arrest at the accident scene, and is the reason why most victims of AOD do not survive.

Because of improvements in prehospital resuscitation, more victims with AOD now survive to reach the ED. ${ }^{4-6}$ Neurological injury is usually severe but there are reports of survivors without neurologic deficits. ${ }^{1,67}$ The stability of the cervical spine is provided by 3 columns: the anterior and posterior longitudinal ligaments maintain the structural integrity of the anterior and middle columns; while the posterior column is held fixed by the ligamenta flava, capsular ligaments, and the nuchal ligament complex. When 2 or all 3 columns are disrupted the spine may move as 2 separate units, increasing the likelihood of spinal cord injury. In AOD without a neurologic deficit, this instability may cause patients to experience the sensation that their "head is falling off." Unstable injuries of the cervical spine, where this is more likely to occur, include a rupture of the transverse ligament of the atlas, a fracture of the odontoid (dens), and a burst fracture with posterior ligamentous disruption (a flexion teardrop fracture).

The radiographic signs of AOD are often subtle and require scrutiny of the lateral cervical spine radiograph for malalignment between the cranium and the spine (Fig. 1). Massive soft-tissue swelling, with widening of the prevertebral soft tissues, is virtually always seen ${ }^{3,6}$ However, the determination of prevertebral soft-tissue widening can be unreliable if the patient has an endotracheal or nasogastric tube in situ.

AOD results in disruption of the normal relationship between the basion (the anterior lip of foramen magnum, and the base of clivus) and the odontoid. In $65 \%$ of AOD cases 
there is anterior dislocation and distraction of the cranium with respect to the cervical spine. ${ }^{3}$

A systematic approach to assessing the cranio-cervical relationship is essential for detecting AOD. The following suggest the presence of AOD on the lateral cervical radiograph.

1. The gap between the occipital condyles and the condylar surface of the atlas is widened to more than $5 \mathrm{~mm}^{3}$

2. The "Wackenheim's Clivus Line," (Fig. 2) a line drawn along the posterior clivus, does not intersect or is not tangential to the odontoid. ${ }^{1,7,8}$

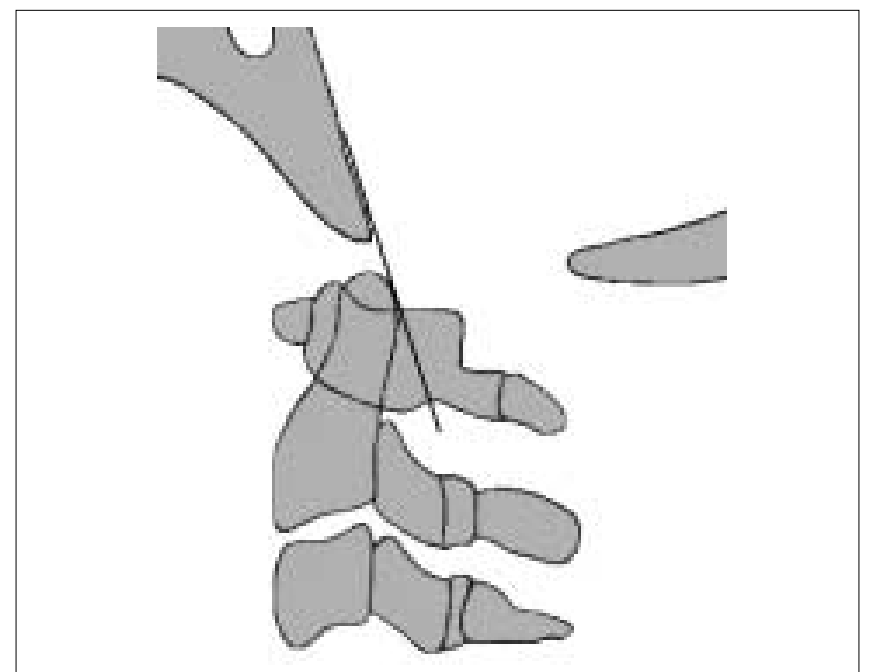

Fig. 2. The Wackenheim's Clivus Line: a line drawn along the clivus should intersect or be tangential to the odontoid. Reproduced, with permission, from reference 8 .

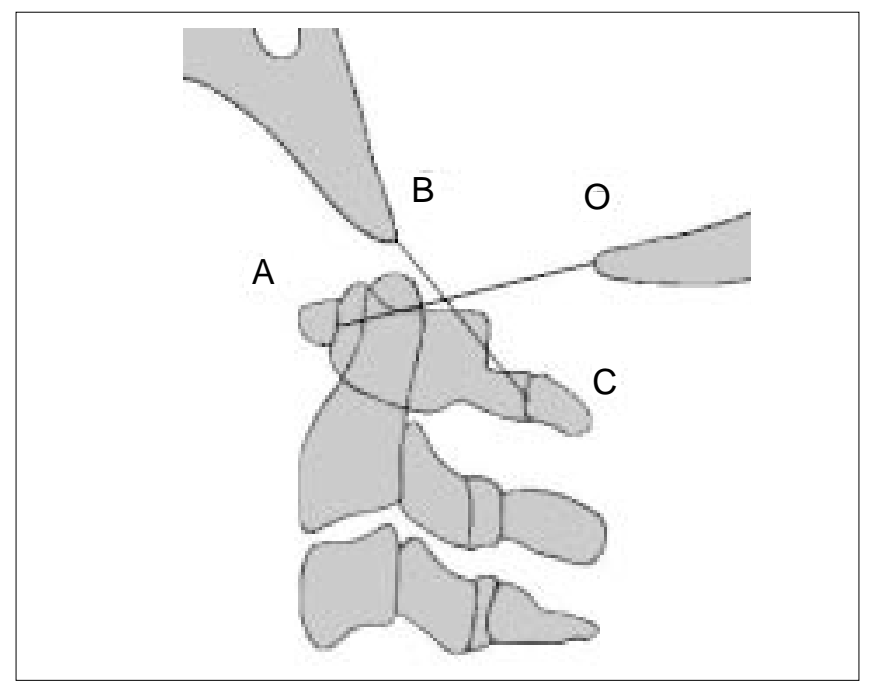

Fig. 3. Power's Ratio: $A=$ the anterior tubercle of the atlas. $\mathrm{B}=$ the basion. $\mathrm{C}=$ the spinolaminar line of the atlas. $\mathrm{O}=$ the opisthion (posterior lip of the foramen magnum). The value $\mathrm{BC} / \mathrm{AO}$ should be less than 1 . Reproduced, with permission, from reference 8 .
3. The "Power's Ratio" is abnormal. This requires identification of 4 bony landmarks. As seen in Figure 3, $\mathrm{A}$ is the anterior tubercle of the atlas; $\mathrm{B}$ is the basion; $\mathrm{C}$ is the spinolaminar line of the atlas; and $\mathrm{O}$ is the opisthion (posterior lip of foramen magnum). The value of $\mathrm{BC} / \mathrm{AO}$ should be less than $1 .^{3}$

4. Harris Criteria: ${ }^{7.8}$

a) The basion is not within $12 \mathrm{~mm}$ of the superior continuation of a line drawn along the posterior cortex of the body of the axis (the posterior-axial line) (Fig. 4).

b) The distance between the basion and the tip of the odontoid is more than $12 \mathrm{~mm}$.

All the radiologic criteria described above have limitations, however, because the bony landmarks may not be clearly seen. CT, particularly with sagittal and coronal reformatting, is the definitive imaging modality to diagnose and evaluate AOD.

\section{Conclusions}

Atlanto-occipital dislocation is a devastating condition that frequently results in prehospital cardiorespiratory arrest and has a high mortality rate. Because of improvements in prehospital care, more patients with AOD now survive to reach the ED. The diagnosis of AOD on plain radiography can be difficult and requires a systematic approach to assessing the cranio-cervical relationship. CT is the defini-

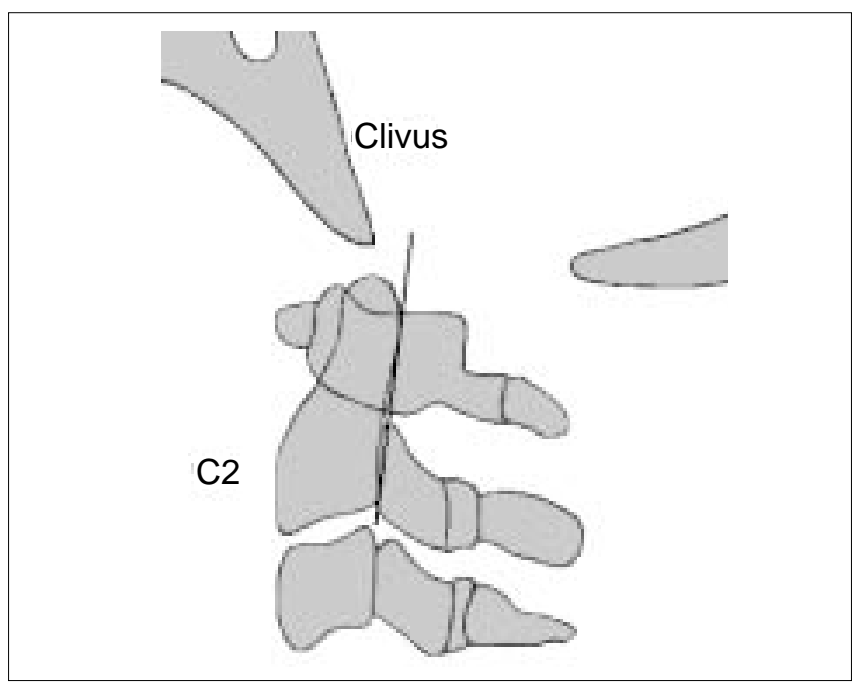

Fig. 4. Harris Criteria: The basion should lie within $12 \mathrm{~mm}$ of the superior continuation of a line drawn along the posterior cortex of the body of the axis (the posterior-axial line). In addition, the distance between the basion and the tip of the odontoid should be less than $12 \mathrm{~mm}$. Reproduced, with permission, from reference 8 . 
tive imaging modality for the diagnosis and evaluation of AOD.

Competing interests: None declared.

\section{References}

1. Ogden JA. Skeletal injury in the child. In: Ogden JA, editor. Spine. 2nd ed. Philadelphia; Saunders Inc: 1990. p. 571-62.

2. Bucholz RW, Burkhead WZ. The pathological anatomy of fatal atlanto-occipital dislocations. J Bone Joint Surg 1979;16-A:248-50.

3. Harris JH Jr, Carson GC, Wagner LK, et al. Radiologic diagnosis of traumatic occipitovertebral dissociation: 2. Comparison of three methods of detecting occipitovertebral relationships on lateral radiographs of supine subjects. AJR Am J Roentgenol 1994; 162:887-92.

4. Maves CK, Souza A, Prenger EC. Traumatic atlanto-occipital disruption in children. Pediatr Radiol 1991;21:504-7.
5. El-Khoury GY, Kathol MH, Daniel WW. Imaging of acute injuries of the cervical spine: value of plain radiography, CT and MR imaging. AJR Am J Roentgenol 1995;164:43-50.

6. Grabb BC, Frye TA, Hedlund GL, et al. MRI diagnosis of suspected atlanto-occipital dissociation in childhood. Pediatr Radiol 1999;29:275-81.

7. Harris JH, Carson GC, Wagner LK. Radiologic diagnosis of traumatic occipitovertebral dissociation: 1 . Normal occipitovertebral relationships on lateral radiographs of supine subjects. AJR Am J Roentgenol 1994;162:881-6.

8. Roche CJ, Carty H. Spinal trauma in children. Pediatr Radiol 2001;31:677-700.

Correspondence to: Dr. David McKenna, Department of Radiology, University College Hospital Galway, Newcastle Road, Galway City, Republic of Ireland; tel 00-353-91-524222, fax 00-353-91-521197, radiolo gyresident@hotmail.com 